Supporting Information

\title{
4,4-Difluoro-4-bora-3a,4a-diaza-s-indacene (BDPI)-Triphenylphosphine Nanoparticles as Photodynamic Antibacterial Agent
}

Hui Wen, ${ }^{\dagger, \ddagger}$ Qihang Wu, ${ }^{\dagger,}$ Chaonan Li, ${ }^{\dagger,}$ Tingting Sun, ${ }^{*}, \dagger$ and Zhigang Xie ${ }^{*, \dagger},+$

† State Key Laboratory of Polymer Physics and Chemistry, Changchun Institute of Applied Chemistry, Chinese Academy of Sciences, Changchun, Jilin 130022, P. R. China

$¥$ University of Science and Technology of China, Hefei 230026, P. R. China

E-mail: suntt@ciac.ac.cn; xiez@ciac.ac.cn 


\section{Materials and Characterizations}

N-iodosuccinimide (NIS) was bought from HEOWNS (Tianjin, China). 1,3-Diphenylisobenzofuran (DPBF) was bought from TCI (Shanghai) Development Co., Ltd.. Triphenylphosphine (TPP) was bought from Tianjin Guangfu Fine Chemical Research Institute. Living cell nucleic acid dyes (SYTO green) and propidium iodide (PI) were purchased from Jiangsu KeyGEN Biotechnology Co., Ltd.. Streptomycin sulfate, broth media and (4,5-dimethylthiazol-2-yl)-2,5diphenyltetrazolium bromide (MTT) were purchased from Shanghai yuanye Bio-Technology Co., Ltd.. ${ }^{1} \mathrm{H}$ NMR spectra were measured in $\mathrm{CDCl}_{3}$ at room temperature by an AV-400 NMR spectrometer from Bruker. Analytical balance (XS105DU) and Rainin Pipettes from METTLER TOLEDO were used to quantify solid and liquid respectively. Confocal laser scanning microscopy (CLSM) images were taken using a Zeiss LSM 700 (Zurich, Switzerland).

\section{Experiments}

Singlet Oxygen Detection. The ability of BDPI-TPP NPs to produce singlet oxygen in vitro were tested by the changes of absorbance of 1,3-diphenylisobenzofuran (DPBF). DPBF was used as a probe molecule to determine the ability of singlet oxygen generation by detecting the quenching of DPBF fluorescence. Briefly, $60 \mu \mathrm{L}$ of DPBF (0.6 mg mL $\mathrm{m}^{-1}$ in N,N-dimethylformamide) was added into BDPI-TPP NPs solution $\left(0.6 \mu \mathrm{g} \mathrm{mL}^{-1}\right.$ in water, $\left.2940 \mu \mathrm{L}\right)$, and only DPBF in water was used as the control. The mixed solution was irradiated with green LED light $\left(12 \mathrm{~mW} \mathrm{~cm}{ }^{-2}\right)$ for 60 
$\mathrm{s}$, and the absorption spectra of the mixed solution were measured every $10 \mathrm{~s}$. The ability of BDPI-Br NPs to produce singlet oxygen in vitro was tested in a similar way.

Bacteria Culture. The single colony on the solid agar was transferred to $3 \mathrm{~mL}$ of broth medium, and the bacteria were in exponential growth stage after shaking at 37 ${ }^{\circ} \mathrm{C}$ for $6 \mathrm{~h}$. The bacteria were centrifuged at $3000 \mathrm{rpm}$ for $4 \mathrm{~min}$ and washed once with phosphate buffer solution (PBS). After discarding the supernatant, the bacteria were suspended in PBS and diluted to an optical density (OD) of 1.0 at $600 \mathrm{~nm}\left(\mathrm{OD}_{600}=1.0\right.$ with about $\left.10^{9} \mathrm{CFU} \mathrm{mL} \mathrm{m}^{-1}\right)$.

Minimal Inhibitory Concentration (MIC) Measurements. The bacteria, $\mathrm{OD}_{600}=1.0$, were diluted to $2 \times 10^{5} \mathrm{CFU} \mathrm{mL}^{-1}$ with broth medium by serial dilution. Broth media containing two-fold serial dilutions of each compound were placed into centrifuge tubes. The bacteria $\left(2 \times 10^{5} \mathrm{CFU} \mathrm{mL}^{-1}, 1 \mathrm{~mL}\right)$ were mixed with different concentrations of BDPI-TPP NPs $(1 \mathrm{~mL}$ per group) and the final bacteria concentration was $10^{5} \mathrm{CFU} \mathrm{mL}^{-1}$, then the mixture was placed into 96 -well plate. The bacteria were irradiated with/without green LED light $\left(12 \mathrm{~mW} \mathrm{~cm}{ }^{-2}\right)$ for $10 \mathrm{~min}$ after being co-cultured at $37{ }^{\circ} \mathrm{C}$ for $30 \mathrm{~min}$. MIC was defined as the minimum concentration of the drug needed to inhibit the visible growth of bacteria after $24 \mathrm{~h}$ at $37^{\circ} \mathrm{C}$

Scanning Electron Microscopy (SEM). SEM was applied to observe the 
morphologies of bacteria treated without or with BDPI-TPP NPs and BDPI-Br NPs. The bacteria, OD600 $=1.0$, were diluted to $2 \times 10^{7} \mathrm{CFU} \mathrm{mL}^{-1}$ with BDPI-TPP NPs or BDPI-Br NPs in broth medium, then the bacteria was immediately fixed with $4 \%$ paraformaldehyde for $30 \mathrm{~min}$. Then the bacteria were centrifuged $(5000 \mathrm{rpm}$ for 5 min), followed by removing the supernatant and resuspending the remaining bacteria in sterile PBS. The samples were dehydrated with a series of graded ethanol solutions $(30 \%, 50 \%, 70 \%, 85 \%$ and $100 \%$, each for $15 \mathrm{~min})$. After $12 \mathrm{~h}$ of drying, the samples were coated with gold and observed by SEM.

Inhibition of Biofilm Formation. The bacteria, OD600=1.0, were treated with the BDPI-TPP NPs $\left(0-6 \mu \mathrm{g} \mathrm{mL}^{-1}\right)$, the final bacteria concentration was $10^{7} \mathrm{CFU} \mathrm{mL} \mathrm{m}^{-1}$. Then the bacteria were irradiated with/without green LED light $\left(12 \mathrm{~mW} \mathrm{~cm}^{-2}\right)$ for 10 min after being co-cultured at $37^{\circ} \mathrm{C}$ for $24 \mathrm{~h}$. The medium in each well was removed and the plates were washed carefully with PBS. The biofilms in each well were stained with $0.02 \%$ crystal violet for $15 \mathrm{~min}$. After the biofilms were washed with deionized water for three times, absolute ethanol $(100 \mu \mathrm{L}$ per well $)$ was added to the plate to solubilize the crystal violet. OD values in each well were read to assess the biofilm formation.

Photodynamic Destruction of Biofilms. The bacteria $\left(10^{7} \mathrm{CFU} \mathrm{mL}^{-1}\right)$ were cultivated in 24 well plates at $37^{\circ} \mathrm{C}$ for one day. After biofilm formation, the medium in each well was discarded, and the plates were washed with PBS for 5 times to 
remove the planktonic bacteria. Fresh medium containing diluted BDPI-TPP NPs (6 $\left.\mu \mathrm{g} \mathrm{mL} \mathrm{L}^{-1}\right)$ or BDPI-Br NPs $(6 \mu \mathrm{g} \mathrm{mL}-1)$ was added to the plates. After incubated at $37{ }^{\circ} \mathrm{C}$ for $30 \mathrm{~min}$, the Light groups were irradiated with green LED light $\left(12 \mathrm{~mW} \mathrm{~cm}{ }^{-2}\right)$ for $10 \mathrm{~min}$. The medium in each well was removed after being incubated for $4 \mathrm{~h}$ and the plates were washed once with PBS, then the bacteria in the biofilm were stained with SYTO and PI. Finally, the biofilms were observed by CLSM.

Wound Infection Healing In Vivo. All animal experiments have been approved (Approved No. 0024) by the Ethics Committee of Changchun Institute of Applied Chemistry, Chinese Academy of Sciences, and carried out according to Animal management regulations approved by the State Science and Technology Commission of the People's Republic of China and Instructive notions with respect to caring for laboratory animals approved by the Ministry of Science and Technology of the People's Republic of China. The female Kunming mice were randomly divided into 6 groups with 5 mice in each group. A round wound ( $1 \mathrm{~cm}$ in diameter) was formed on the back skin of each mouse. $30 \mu \mathrm{L}$ of the suspended $S$. aureus solution was inoculated on the wound to form an infection model. After infection, $30 \mu \mathrm{L}$ of PBS/BDPI-TPP NPs/BDPI-Br NPs were added to the wounds, respectively. The mice in the light groups (TPP-L, Br-L, PBS-L) were exposed to light (12 $\left.\mathrm{mW} \mathrm{cm}^{-2}, 10 \mathrm{~min}\right)$ after being incubated for $30 \mathrm{~min}$ and the mice in the dark groups (TPP-D, Br-D, PBS-D) were not irradiated. In the process of wound healing, the wounds were photographed and monitored every day, and the wound areas were measured by 
Image $\mathrm{J}$ software. On the 6th day after treatments, the wound tissues were harvested and the numbers of bacteria in the wounds were measured by plate counting method. The tissues were immersed in $2 \mathrm{~mL}$ of sterile PBS, and the bacterial suspensions were obtained by ultrasonic treatment. $20 \mu \mathrm{L}$ of the suspension was placed on agar plates for bacterial growth. Finally, hematoxylin\&eosin (H\&E) staining was employed to evaluate the therapeutic effect.

Biosafety Analysis of BDPI-TPP NPs In Vitro and In Vivo. For the in vitro biosafety evaluation, mouse fibroblasts (NIH 3T3 cells) were inoculated into a 96 well plates and cultured until the cells adhered to the wall. Different concentrations of BDPI-TPP NPs $(0-0.3 \mu \mathrm{g} \mathrm{mL}-1)$ were added into the plates, and the cells were cultured for $24 \mathrm{~h}$, then MTT ( $20 \mu \mathrm{L}$ in each well) was added. After $4 \mathrm{~h}$, culture media in each well were removed and DMSO (150 $\mu \mathrm{L}$ in each well) was added. Finally, the plate was shaken for $3 \mathrm{~min}$ and the absorbance at $490 \mathrm{~nm}$ was measured via a microplate reader.

For the in vivo biosafety evaluation, healthy Kunming mice were randomly divided into 3 groups with 3 mice in each group and treated with PBS, BDPI-Br NPs, BDPI-TPP NPs with $200 \mu \mathrm{L}$ each mouse. On the 6th day, the main organs including heart, liver, spleen, lung and kidney were collected and stained with hematoxylin and eosin (H\&E) for histological examinations. 


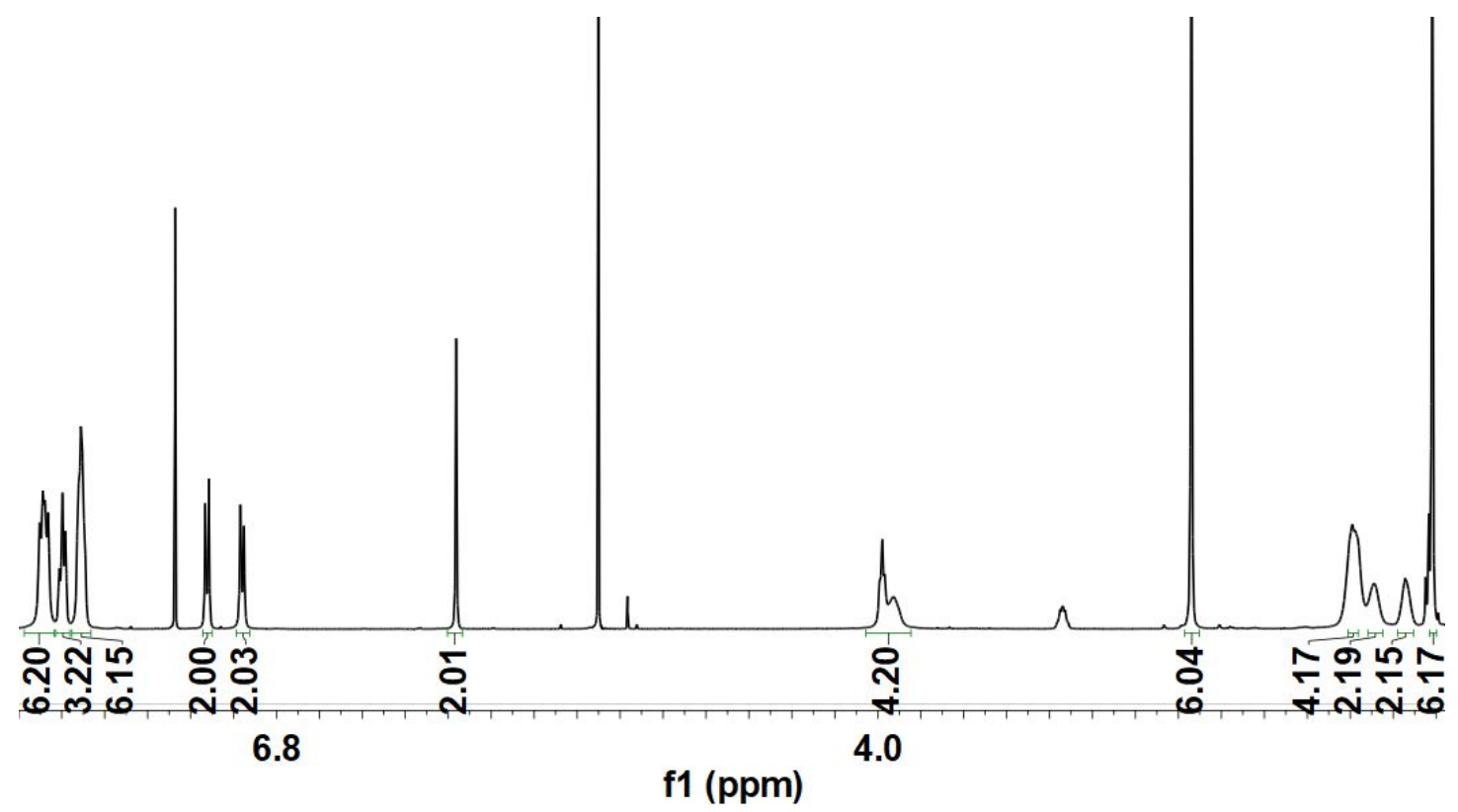

Figure S1. The ${ }^{1} \mathrm{H}$ NMR spectrum of BDP-TPP.

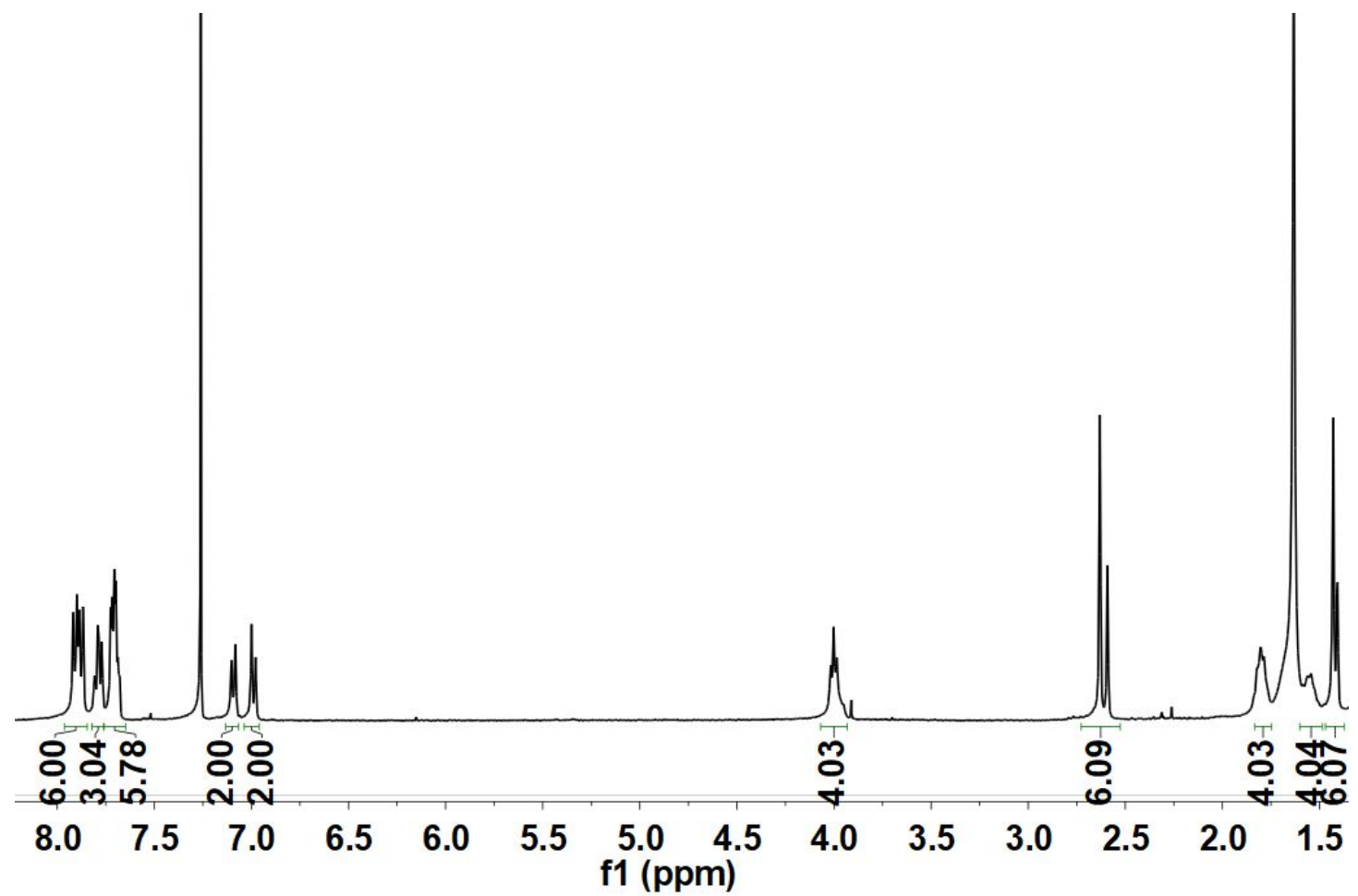

Figure S2. The ${ }^{1} \mathrm{H}$ NMR spectrum of BDPI-TPP. 


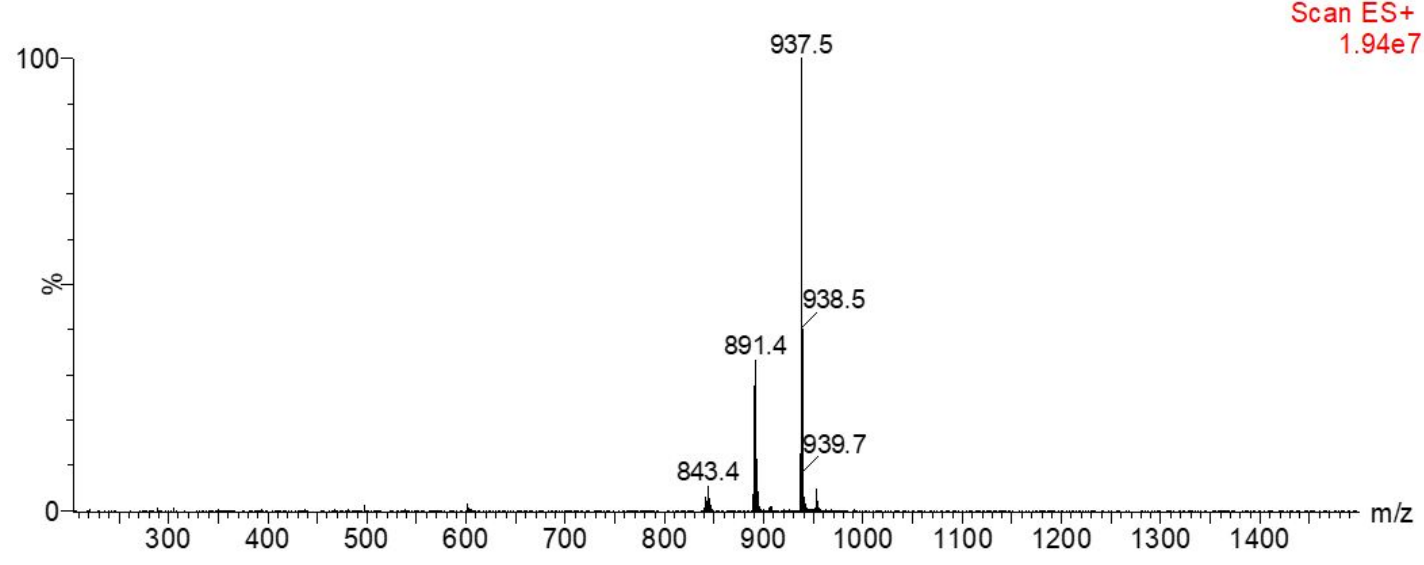

Figure S3. The ESI-MS spectrum of BDPI-TPP.

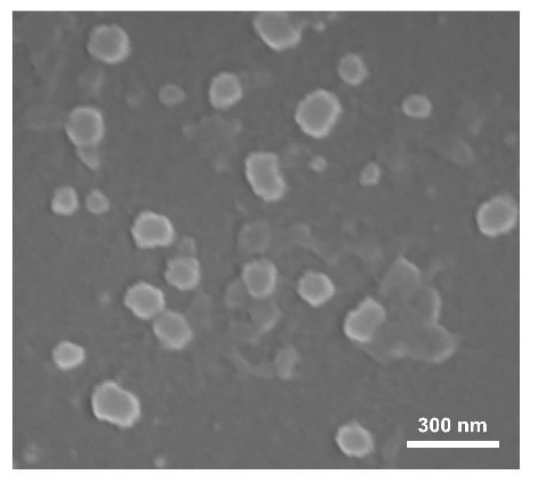

Figure S4. SEM image of BDPI-TPP NPs. 


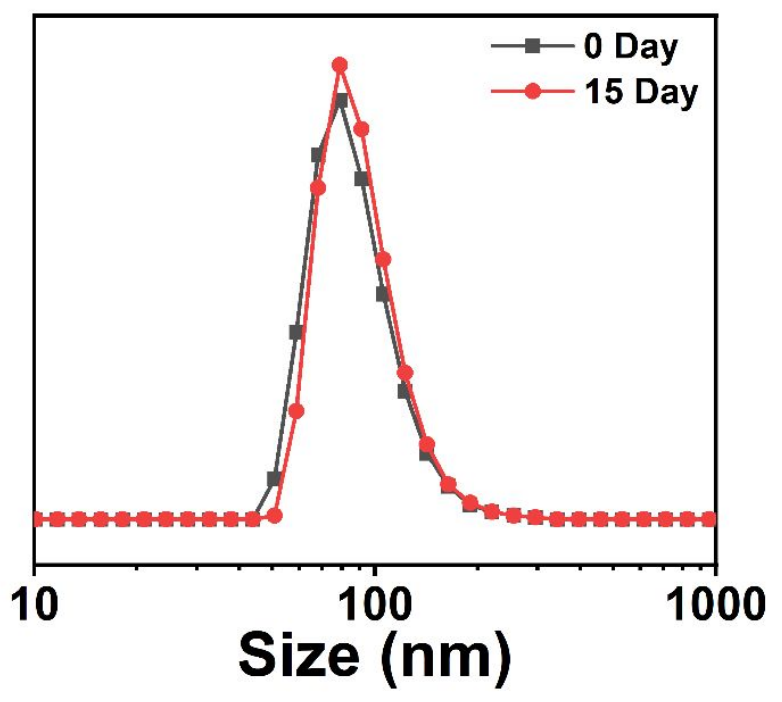

Figure S5. The size of BDPI-TPP NPs after 15 days of storage at $4{ }^{\circ} \mathrm{C}$ by DLS.

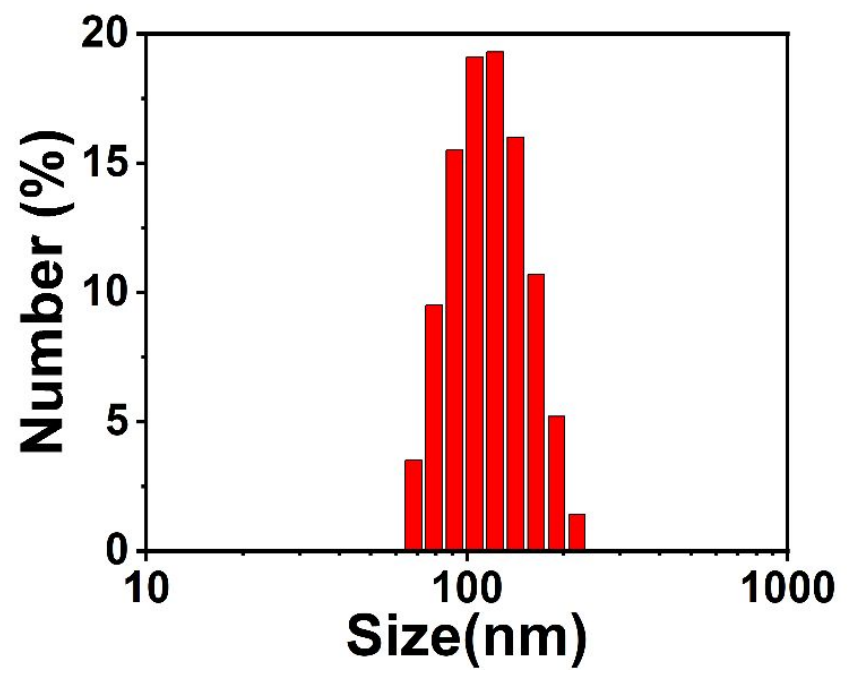

Figure S6. Size distribution of BDPI-Br NPs characterized by DLS. 


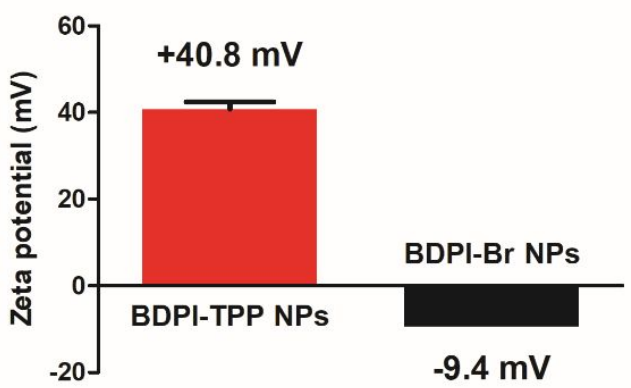

Figure S7. The zeta potential of BDPI-TPP NPs and BDPI-Br NPs.

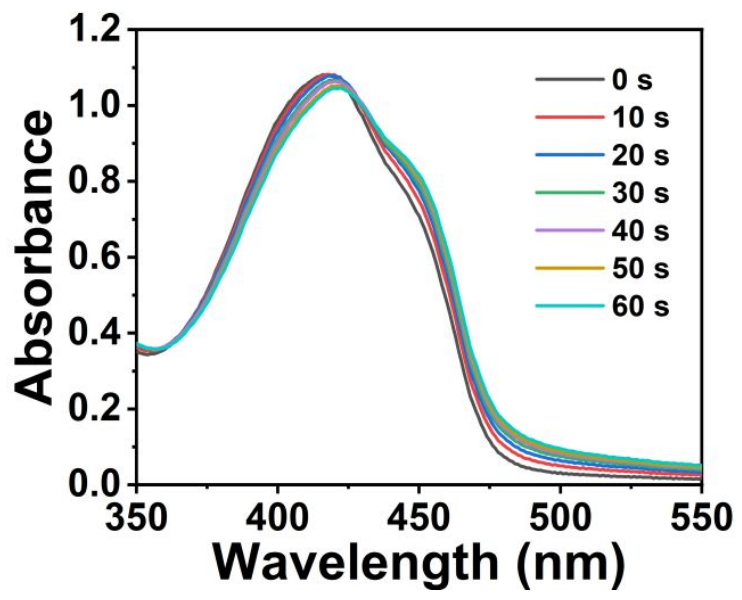

Figure S8. The bleaching of DPBF over time under green light irradiation (12 $\mathrm{mW}$ $\left.\mathrm{cm}^{-2}\right)$. 

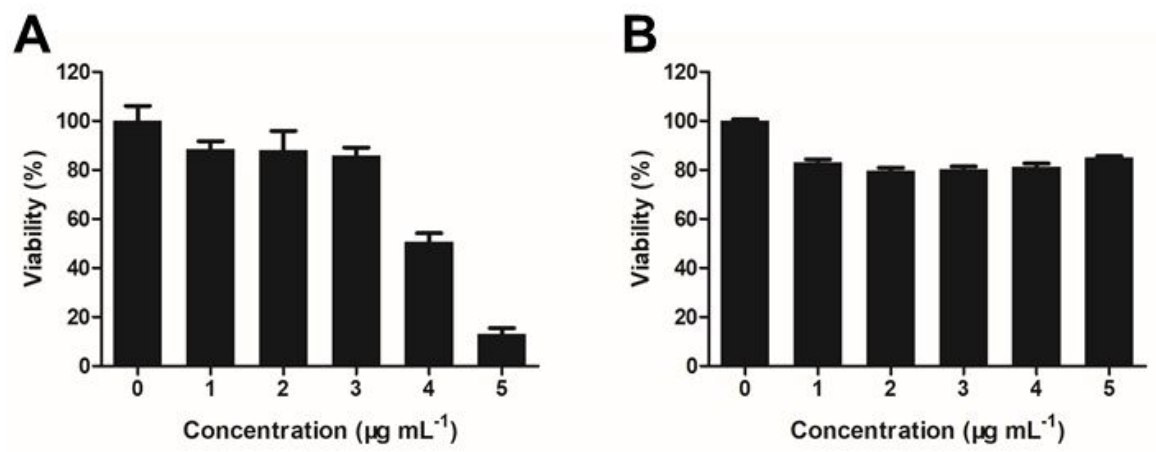

Figure S9. The antibacterial activity of different concentrations of (A) BDPI-TPP NPs $\left(0-5 \mu \mathrm{g} \mathrm{mL}^{-1}\right)$ and (B) BDPI-Br NPs $\left(0-5 \mu \mathrm{g} \mathrm{mL}^{-1}\right)$ against $S$. aureus without irradiation.

A

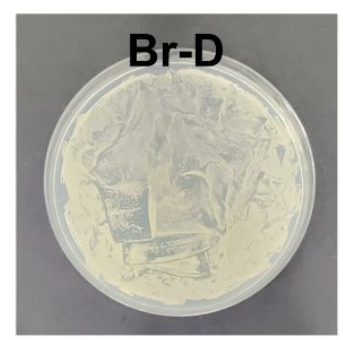

B

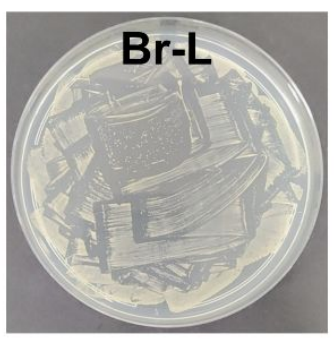

Figure S10. Photographs of bacteria colonies from $S$. aureus treated with BDPI-Br NPs with green light illumination or not.

A

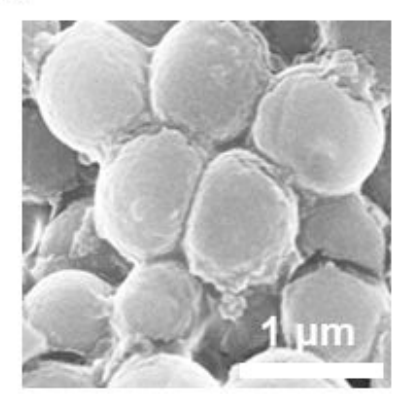

B

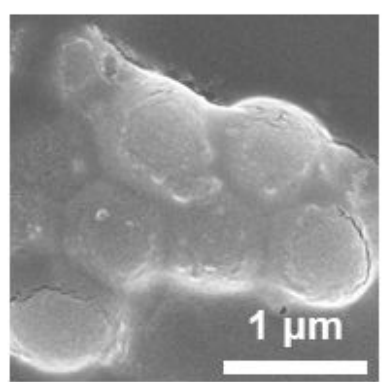

Figure S11. SEM images of $S$. aureus treated with BDPI-Br NPs with green light 
irradiation (12 $\left.\mathrm{mW} \mathrm{cm}^{-2}, 10 \mathrm{~min}\right)(\mathrm{B}) \operatorname{or} \operatorname{not}(\mathrm{A})$.

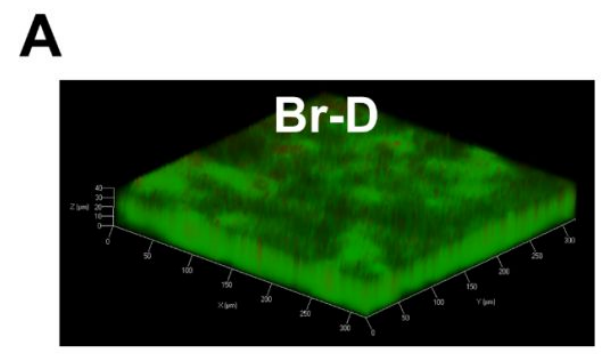

B

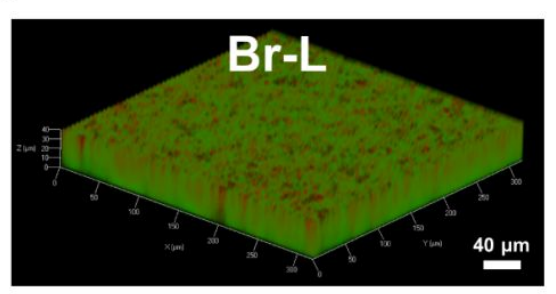

Figure S12. 3D CLSM images of the biofilms treated with BDPI-Br NPs $\left(6 \mu \mathrm{g} \mathrm{mL}^{-1}\right)$ with green light illumination (12 $\left.\mathrm{mW} \mathrm{cm}^{-2}, 10 \mathrm{~min}\right)$ or not.

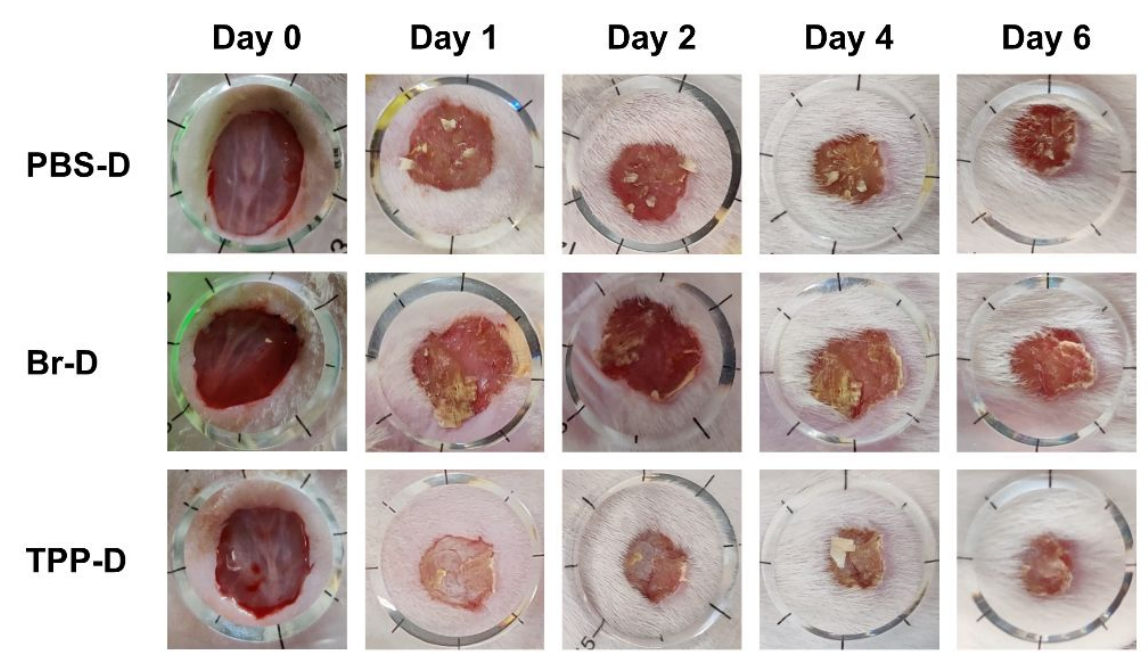

Figure S13. Photos of the wounds infected with S. aureus in PBS-D, Br-D and TPP-D groups. 